\title{
Assessment of Meteorological Drought Hazard Area using GIS in Ghareh Aghaj basin, Iran
}

\section{${ }^{1}$ ABDOL RASSOUL ZAREIEE; ${ }^{2}$ MASOUD MASOUDI; ${ }^{3}$ MANSUR TAGHVAEI; ${ }^{3}$ RASHID FALLAH SHAMS; ${ }^{3}$ ARMAN GANJEI}

\author{
${ }^{* 1}$ Department of Desert Zones Management, Agricultural College, Shiraz University, Iran \\ ${ }^{2,3}$ Department of Desert Zones Management, Agricultural College, Shiraz University, Iran
}

\begin{abstract}
In this paper area under hazard of Meteorological Drought was evaluated using GIS technique. In Ghareh Aghaj watershed, meteorological drought has the most profound effect on the way of living and regional economy. Hence knowledge of the meteorological drought hazard area of their occurrence and their course is an essential aspect for planning. The purpose of this study was to make a model of the meteorological drought hazard area using GIS. A set of meteorological drought indices were studied and reviewed to define areas under hazard. Meteorological drought indicators used in the present model include: Annual rainfall, climate change, Coefficient variation $(\mathrm{CV})$ of annual rainfall, climate, ratio of the number of arid years with SPI $<-1$ to the number of total years in each station, ratio of the number of vernal arid seasons with $\mathrm{SPI}<-1$ to the number of total years in each station, and the number of sequential arid years using definition of WMO. The data analyzed have been gathered from the records, reports and maps published by the governmental offices of Iran. Most of these indicators were performed using average annual rainfall data and average annual temperature of minimum 16 years record of 20 stations. Each of the hazard indicator maps and also final hazard map are classified into 4 hazard classes of drought: mild, moderate, severe and very severe. The final hazard classes were defined on the basis of hazard scores arrived at by assigning the appropriate attributes to the indicators and the final hazard map was prepared by overlaying different hazard indicator maps in the GIS, deploying the new model. The final Hazard Map shows that moderate hazard areas (67\% of the basin) are much widespread than areas under severe hazard (37\% of the basin) which are observed in the Southeast of the region. @JASEM
\end{abstract}

The eighth National Economic and Social Development Plan (1992-1996) called for achievement of water resource sustainability (NESDB 1992). The plan describes development issues and problems with the guidelines for developing water resources. Meteorological Drought risk area is a result of a variety of factors. Drought generally originates from less precipitation over an extended period of time. These include occurrence of the lack of the rain in the rainy season, number and amount of rainfall and other climatic anomalies. Palmer (1965) identified monthly index values for past dry periods to yield an equation for calculating drought severity in four classes. In an operational definition of drought it identifies drought from impact data (i.e. crop damage). It is widely accepted that combination of physical nature of area, amount of rainfall and water resource development leads to identify the drought pattern.

The shortage of the rainfall, the erratic distribution of the rainfall, highs evapoteranspiration, water erosion, low water holding capacity of soil that all of them are the major causes of drought. It concluded that the meteorological drought based on the number of days with rainfall be less than specified threshold. Department of Environmental Planning and Policy (DEPP) (1996) established the drought risk areas in the northeast of Thailand using GIS for spatial overlay of variable layers: rainfall index, soil water holding capacity, irrigated area, ground water yield, rainfall probability and land use. There is still a gap in the methods used and details of the thematic layers established. Another study of rainfall in the northeast of Thailand made by Siripon and Mongkolsawat (2000) concludes that the unevenly distributed rainfall during the rainy season is found extensively and extends longer period in the southwest and the central part of the region. This phenomenon is frequently occurred in the second half of June and September for the areas in southwest and northeast of the region respectively. The information obtained from limited studies still requires a more detailed identification of spatial pattern of drought. This is the support of the government in allocating water for rural consumption more accurately and in the suitable place. Computer-based analysis and GIS can address this issue with higher accuracy, based on the integration of meteorological data of the areas. The purpose of this study is to make the model of drought hazard area using GIS with a set of indicators empirically evaluated.

\section{MATERIAL AND METHODS}

Study Area: Ghareh Aghaj watershed, is one of the main watersheds in Fars province in southwest of Iran. This region covers about one-ninth of the total area of the province. Area of this region is 12649 $\mathrm{km}^{2}$. It lies between Lat. $28^{\circ}, 22^{\prime}$ and $29^{\circ}, 55^{\prime} \mathrm{N}$ and Long. $51^{\circ}, 48^{\prime}$ and $54^{\circ}, 24^{\prime} \mathrm{E}$ (Fig.1). Mean annual rainfall is about 320.54 (mm. /year). Ghareh Aghaj watershed contains one-sixth of the total population 
of the Fars province. Over $60 \%$ of the population is engaged in agriculture which dominated by irrigated cultivation and secondary stage by dry cultivation production. At the present time, less than $10 \%$ of the cultivated land in the ranges is dry cultivation. In addition, water shortage for domestic consumption is usually identified as principal constraint for the people during the dry season. Lack of the water or drought in the region has profound impact that can be listed as economic, social and environmental.

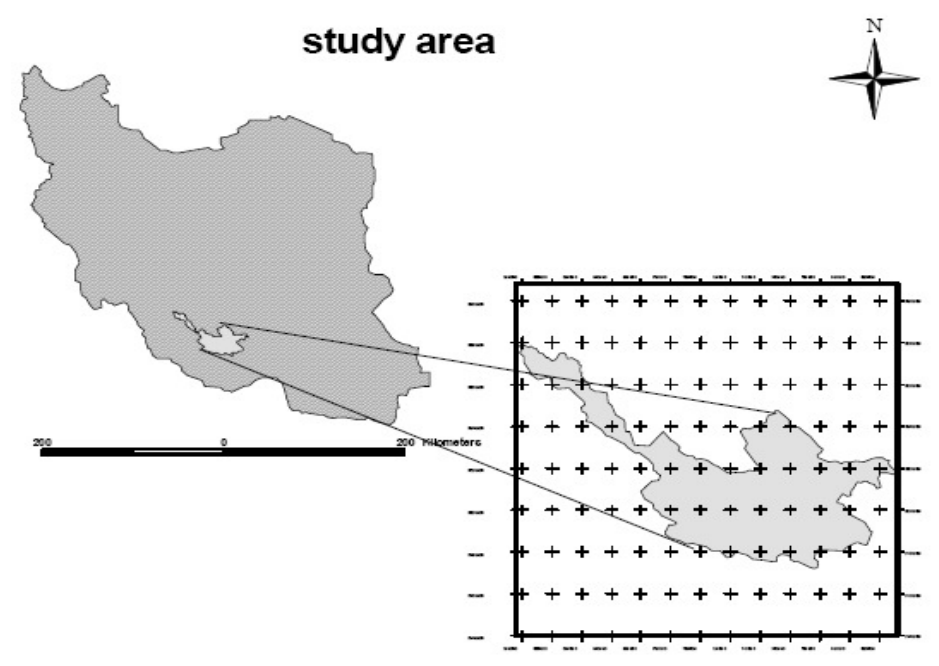

Figure 1. Study area

Methodology: The data obtained were of two types 1) numerical data and 2) thematic maps, but mainly in the numerical format. All such relevant data were obtained from the local and main offices and institutes of the Ministries of Agriculture and Energy and Organization of Meteorology of Iran and processed thoroughly, using the GIS technique (Software of Arc View). The thematic maps were digitized and some numerical data related to the meteorological stations of region have been considered for the basin to further prepare different hazard indicator maps. Annual rainfall and temperature data from 20 stations in Ghareh Aghaj watershed with at least 16 years records were compiled to analyze the indicators. Then Thiessen method was used to determine the Regions influence with each station. The assessment of the hazard of meteorological drought has been attempted by first identifying the main indicators of meteorological drought in the study area and then establishing the thresholds (class limits) of severity for indicators and in the end analyzing the hazard. The recommendations appearing in some literature (like Masoudi et al. 2007) as well as the statistically suitable parameters of region and country like average and standard deviation for some indicators have also been taken into consideration while fixing the thresholds of the four classes of severity (ratings scores between 1 to 4) for each indicator. Seven indicators (Table 1) have been processed in the GIS to arrive at the hazard map for each indicator. The indicators are related to a period of time (like climate map) describing current state of hazard or trend of degradation in a period of time (like climate change map). In order that the effect of all the indicators gets projected in the final hazard map, the overlays of the individual hazard indicator maps (Fig. 2), derived from seven indicators, were analyzed step by step (Fig. 3). The severity of hazard assigned to each polygon has been assessed by summing all the attributes (rating scores) of indicators used in the GIS. Such a method has been conventionally used for preparing the hazard and risk maps for different types of land degradation (Grunblatt et al. 1992; Kumar 1992 Singh et al. 1992; Ahmadi 1995; Ahmadi et al. 2001; Feiznia et al. 2001; and Zehtabian \& Jafari 2002). The following equation was used in GIS to assess the hazard map of meteorological drought: Hazard score for meteorological drought = $[$ (Climate Score $)+($ Annual rainfall Score $)+($ Climate Change Score $)+(1.5 \times$ Coefficient variation Score $)+$ $(1.5 \times$ ratio of vernal arid seasons Score $)+(2 \times$ ratio of arid years Score $)+(2 \times$ Drought Hazard Score $)] /$ 10 

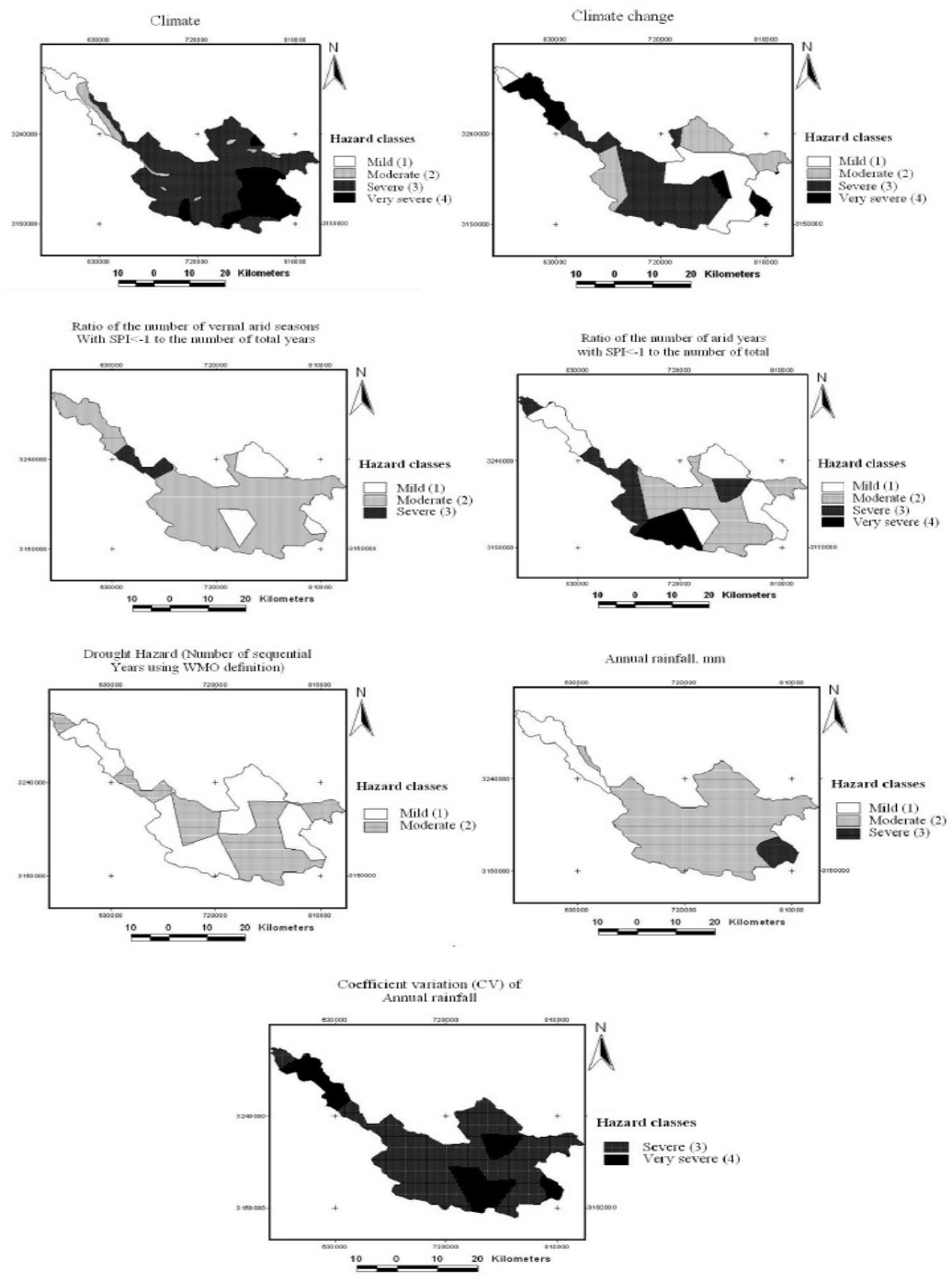

Figure 2. hazard indicator maps

It's necessary to say that about the overly of the hazard layers according to the importance of indices, we should apply a revisory coefficient. The hazard score in each polygon denotes the cumulative effect of all the indicators for qualifying the five severity classes (Table 2). This facilitated the production of Fig. 4 that showed the different degrees of Hazard of meteorological drought.

\section{RESULTS AND DISCUSSION}

Most studies so far done in Iran and in the world have based their estimation on the 'present state' of hazard of drought during the specific year using some indices like SPI. Such Indicator maps or information alone based on the present state of hazard derived from the specific year are inadequate to show those areas which are more vulnerable to the hazard. It requires a combination of more indices of hazard like number of sequential years of hazard, climate change and ratio of vernal arid seasons showing different aspects of hazard. This kind of classification using different indicators which some of them have not been used in other literatures for such studies is the first attempt of its kind for defining areas with higher risk drought. The GIS analysis not only facilitated the model those development but also allowed the evaluation of spatial correlation and hazard map production. 
Table 1. Indicators used in the Evaluation of Meteorological Drought Hazard

\begin{tabular}{|c|c|c|c|c|}
\hline \multirow[t]{2}{*}{ Indicators } & \multicolumn{4}{|c|}{ Class limits and their rating score } \\
\hline & Slight (1) & Moderate (2) & Severe (3) & Very severe (4) \\
\hline $\begin{array}{l}\text { 1) Drought Hazard } \\
\text { (Number of sequential years using WMO } \\
\text { definition)* }\end{array}$ & $0-1$ & $2-3$ & $4-5$ & $\geq 6$ \\
\hline 2) Climate & $\begin{array}{l}\text { Sub humid and } \\
\text { humid }\end{array}$ & Mediterranean & Semi arid & Arid and Very arid \\
\hline 3) Annual rainfall, $\mathrm{mm}$ & $\geq 500$ & $250-499$ & $100-249$ & $<100$ \\
\hline $\begin{array}{l}\text { 4) Climate Change } \\
\text { (significant change in annual temperature } \\
\text { trend during } 100 \text { years and significant } \\
\text { change in climatic index trend)** }\end{array}$ & $\begin{array}{l}\text { No change or } \\
<1^{\text {OC }} \text { increase in } \\
\text { temperature }\end{array}$ & $\begin{array}{l}\text { between } 1-4^{\mathrm{OC}} \\
\text { increase in } \\
\text { temperature }\end{array}$ & $\begin{array}{l}>4^{\mathrm{OC}} \text { increase } \\
\text { in temperature } \\
\text { or change in } \\
\text { climate toward } \\
\text { drier condition }\end{array}$ & $\begin{array}{l}>4^{\mathrm{OC}} \text { increase in } \\
\text { temperature and } \\
\text { change in climate } \\
\text { toward drier condition }\end{array}$ \\
\hline $\begin{array}{l}\text { 5)Coefficient variation }(\mathrm{CV}) \text { of annual } \\
\text { rainfall } * * *\end{array}$ & $<20$ & $20-29$ & $30-39$ & $\geq 40$ \\
\hline $\begin{array}{l}\text { 6)ratio of the number of arid years with } \\
\text { SPI }<-1 * * * * \text { to the number of total years }\end{array}$ & $<12$ & $12-19.99$ & $20-23.99$ & $\geq 24$ \\
\hline $\begin{array}{l}\text { 7) ratio of the number of vernal arid seasons } \\
\text { with SPI }<-1 \text { to the number of total years }\end{array}$ & $<9.99$ & $10-19.99$ & $20-24.99$ & $\geq 25$ \\
\hline
\end{tabular}

*Drought year is when rainfall is less than $60 \%$ of normal and continues two years; **Climatic index: Domartan index for this research, $\mathrm{I}=\mathrm{P} /(\mathrm{T}+10) ; * * * \mathrm{CV}=($ Standard deviation of rainfall $/$ Average rainfall $) \times 100 ; * * * * \mathrm{SPI}=($ total rainfall in a year- average of annual rainfall) / standard deviation of period

Table 2. The severity classes of hazard Map produced in the GIS.

\begin{tabular}{|c|c|c|c|c|}
\hline Class & Slight & Moderate & Severe & Very severe \\
\hline Hazard score & $<1.49$ & $1.5-2.49$ & $2.49-3.49$ & $\geq 3.5$ \\
\hline
\end{tabular}

The hazard map of the Qareh Aghaj (Fig. 4) shows different hazard classes. From the Fig. 4 and Table 3 a general conclusion can be derived that in the Qareh Aghaj basin a smaller proportion $(37 \%)$ is under 'severe hazard' of drought while the widespread areas are under moderate risk of drought (63\%). On the other hand Table 3 shows among the hazard indicator maps used in the model, climate and climate change maps show the most hazardous while drought hazard map based on the number of sequential years shows the least hazardous, indicating drought hazard in the area doesn't continue so long.

Conclusion: Preparation of a Hazard Map is seen as a prerequisite for planning agricultural and environmental conservation. For the entire arid and semi arid parts of Iran, highly threatened by drought, it is the need of the day. The Qareh Aghaj Basin model is the first attempt of its kind for defining the real hazard of drought and can be made applicable for other areas in Iran and elsewhere. This model has been applied for a regional scale but if the data of indicators for smaller scales are available, it can be used also to measure hazard for smaller areas. The main results of the present paper are:

1. The hazard maps of seven indicators give a far better opportunity to distinguish the severity classes of hazard of drought. This kind of map shows areas under different classes of vulnerability and risk of drought and differs from those maps showing current state of hazard.

2. Considering both severe and moderate hazardous areas it is concluded that the areas under severe hazard cover about $37 \%$ of the total basin, while those under moderate hazard have a greater spread $(63 \%)$.

3 . The remedial measures should be undertaken by selecting the priority areas. Areas under severe hazard (indicated in the hazard map) will be the areas needing immediate attention.

Acknowledgements: The authors are thankful to the Government Offices of Iran, for providing the data, maps and reports for this hazard assessment work. 
Table 3. Percent area under hazard classes of meteorological drough and different hazard indicator maps in the Qareh Aghaj basin

\begin{tabular}{|c|c|c|c|c|c|}
\hline \multirow{2}{*}{ Indicators } & \multicolumn{5}{|c|}{ Geographical extent (in \%) for the hazard classes } \\
\hline & Mild & moderate & Severe & Very severe & Total \\
\hline $\begin{array}{l}\text { 1) Drought Hazard (Number of sequential years using WMO } \\
\text { definition) }\end{array}$ & $54.21 \%$ & $45.79 \%$ & 0 & 0 & $100 \%$ \\
\hline 2) Climate & $7.3 \%$ & $5.2 \%$ & $66.4 \%$ & $21.1 \%$ & $100 \%$ \\
\hline 3) Annual rainfall, $\mathrm{mm}$ & $12 \%$ & $83 \%$ & $5 \%$ & 0 & $100 \%$ \\
\hline $\begin{array}{l}\text { 4) Climate Change (significant change in annual temperature } \\
\text { trend during } 100 \text { years and significant change in climatic } \\
\text { index trend) }\end{array}$ & $26 \%$ & $21 \%$ & $40 \%$ & $13 \%$ & $100 \%$ \\
\hline 5)Coefficient variation (CV) of annual rainfall & 0 & 0 & $74 \%$ & $26 \%$ & $100 \%$ \\
\hline $\begin{array}{l}\text { 6)ratio of the number of arid years with } \mathrm{SPI}<-1 \text { to the number } \\
\text { of total years }\end{array}$ & $22.56 \%$ & $37.56 \%$ & $24.56 \%$ & $15.32 \%$ & $100 \%$ \\
\hline $\begin{array}{l}\text { 7) ratio of the number of vernal arid seasons with } \mathrm{SPI}<-1 \text { to the } \\
\text { number of total years }\end{array}$ & $19.21 \%$ & $73.06 \%$ & $7.73 \%$ & 0 & $100 \%$ \\
\hline Meteorological drought Hazard & 0 & $63 \%$ & $37 \%$ & 0 & $100 \%$ \\
\hline
\end{tabular}

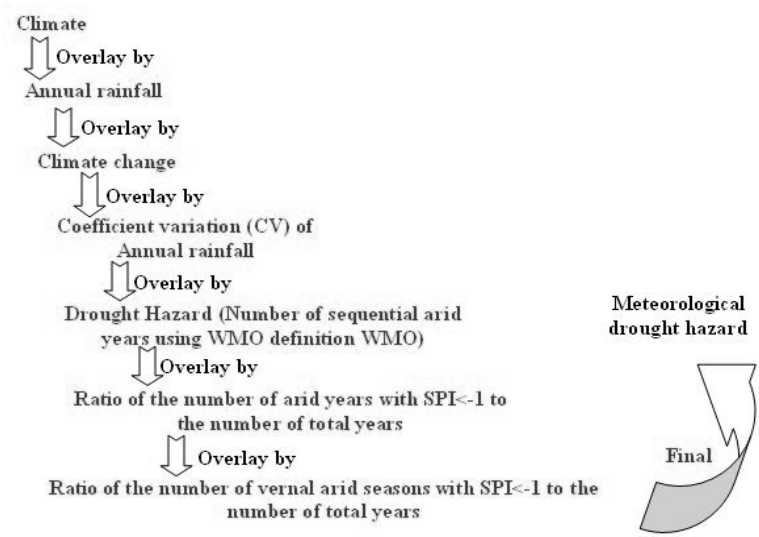

Fig 3. Schematic chart of meteorological drought analysis

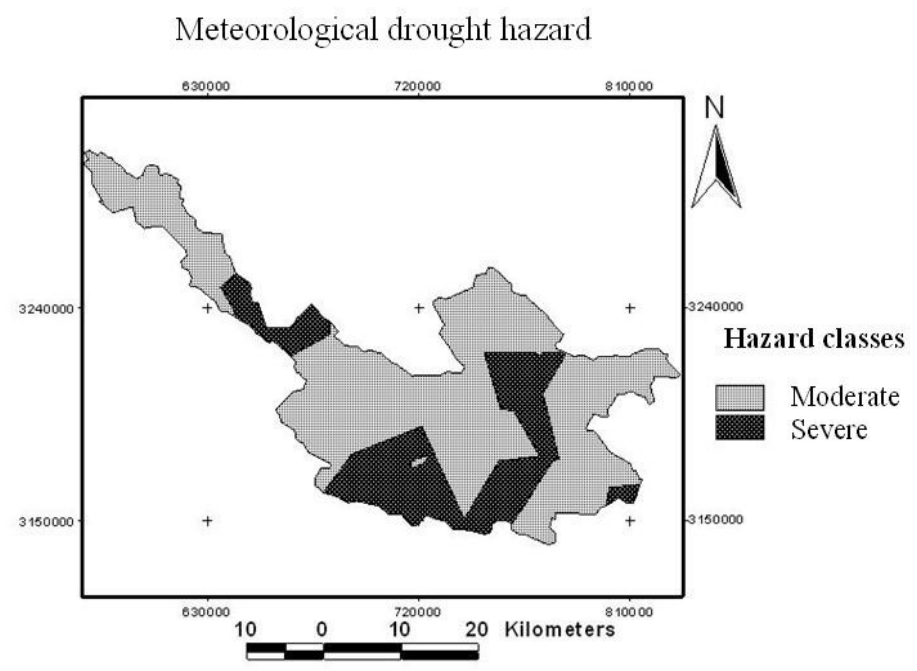

Fig 4. Hazard of Meteorological Drought in the Qareh Aghaj basin

ABDOL RASSOUL ZAREIEE; MASOUD MASOUDI; MANSUR TAGHVAEI; RASHID FALLAH SHAMS; ARMAN GANJEI 


\section{REFERENCES}

Ahmadi, H., 1995: Applied geomorphology. Tehran University Publication, 613pp

Ahmadi, H., Abbas Abadi, M.R., Onagh, M., and M.R. Ekhtessasi, 2001: Quantitative assessment of desertification in Aghqalla and Gomishan Plain for creation of a regional model. Iranian J. Natural Resources, 54, 3-22.

DEPP, 1996: Flood and Natural Risk Area in Northeast Thailand Project Bangkok. Min. of Science, Technology and Environment.

Feiznia, S., Gooya, A.N., Ahmadi, H., and H. Azarnivand, 2001: Investigation on desertification factors in Hossein-Abad Mish Mast plain and a proposal for a regional model. Journal of Biaban, 6, 1-14.

Grunblatt, J., Ottichilo, W. K., and R.K. Sinange, 1992: A GIS approach to desertification assessment and mapping. Journal of Arid Environments, 23, 81-102.

Kumar, S., 1992: Assessment of vegetation degradation: status of methodological research. Annals of Arid zone, 31, 53-62.
Masoudi, M., Patwardhan, A.M., and S.D. Gore, 2007: Risk assessment of lowering of ground water table using GIS for the Qareh Aghaj Sub Basin, Southern Iran. Journal of the Geological Society of India, 70, 861-872

NESDB, 1992: The eight National Economic and Social Development Plan. Office of the Prime Minister, Bangkok.

Palmer, 1965: Meteorological Drought, Office of climatology. Washington D.C., U.S. Weather Bureau, Research paper No. 45, 58pp.

Singh, S., Kar, A., Joshi, D.C., Ram, B., Kumar, S., Vats, P.C., Singh, N., Raina, P., Kolarkar, A.S., and R.P. Dhir, 1992: Desertification mapping in Western Rajasthan. Annals of Arid Zone, 31, 237-246.

Siripon, K., and C. Mongkolsawat, 2000: Spatial and Temporal Analysis of Rainfall Pattern in Northeastern Thailand: Application of GIS. Journal of Remote Sensing and GIS, Association of Thailand, 1(1), 1-18.

Zehtabian, G., and R. Jafari, 2002: Evaluation of water resources degradation in Kashan area using desertification model. Journal of Ecology, 30, 19-30. 